\title{
Fluid management in critically ill patients: the role of extravascular lung water, abdominal hypertension, capillary leak, and fluid balance
}

\author{
Colin Cordemans ${ }^{1}$, Inneke De laet ${ }^{1}$, Niels Van Regenmortel ${ }^{1}$, Karen Schoonheydt ${ }^{1}$, Hilde Dits ${ }^{1}$, Wolfgang Huber²,
} Manu LNG Malbrain ${ }^{1 *}$

\begin{abstract}
Introduction: Capillary leak in critically ill patients leads to interstitial edema. Fluid overload is independently associated with poor prognosis. Bedside measurement of intra-abdominal pressure (IAP), extravascular lung water index (EVLWI), fluid balance, and capillary leak index (CLI) may provide a valuable prognostic tool in mechanically ventilated patients.
\end{abstract}

Methods: We performed an observational study of 123 mechanically ventilated patients with extended hemodynamic monitoring, analyzing process-of-care variables for the first week of ICU admission. The primary outcome parameter was 28-day mortality. $\Delta_{\max } E V L W V$ indicated the maximum difference between EVLWI measurements during ICU stay. Patients with a $\Delta_{\max } E V L W I<-2 \mathrm{~mL} / \mathrm{kg}$ were called 'responders'. CLI was defined as C-reactive protein (milligrams per deciliter) over albumin (grams per liter) ratio and conservative late fluid management (CLFM) as even-to-negative fluid balance on at least two consecutive days.

Results: CLI had a biphasic course. $\Delta_{\max } E V L W I$ was lower if CLFM was achieved and in survivors $(-2.4 \pm 4.8$ vs $1.0 \pm$ $5.5 \mathrm{~mL} / \mathrm{kg}, p=0.001 ;-3.3 \pm 3.8$ vs $2.5 \pm 5.3 \mathrm{~mL} / \mathrm{kg}, p=0.001$, respectively). No CLFM achievement was associated with increased CLI and IAP mean on day 3 and higher risk to be nonresponder (odds ratio (OR) 2.76, $p=0.046 ; \mathrm{OR} 1.28$, $p=0.011$; OR 5.52, $p=0.001$, respectively). Responders had more ventilator-free days during the first week ( $2.5 \pm 2.3$ vs $1.5 \pm 2.3, p=0.023)$. Not achieving CLFM and being nonresponder were strong independent predictors of mortality (OR 9.34, $p=0.001$ and OR 7.14, $p=0.001$, respectively).

Conclusion: There seems to be an important correlation between CLI, EVLWI kinetics, IAP, and fluid balance in mechanically ventilated patients, associated with organ dysfunction and poor prognosis. In this context, we introduce the global increased permeability syndrome.

\section{Introduction}

Acute inflammatory injury incites a cascade of proinflammatory mediators leading to microcirculatory dysfunction, capillary leak, and distributive shock $[1,2]$. Although in the early stage of shock liberal and goal-directed fluid therapy is mandated [3], subsequent (over)resuscitation increases microvascular hydrostatic pressure and may promote interstitial fluid accumulation [4-6]. This fluid overload is independently associated with impaired organ

\footnotetext{
* Correspondence: manu.malbrain@skynet.be

'Department of Intensive Care, Ziekenhuis Netwerk Antwerpen, Campus

ZNA Stuivenberg, Lange Beeldekensstraat 267, 2060 Antwerpen 6, Belgium

Full list of author information is available at the end of the article
}

function, intra-abdominal hypertension (IAH), and poorer outcome [7-15]. Conversely, a conservative fluid strategy limiting fluid intake and even promoting fluid removal improved clinical outcomes [16].

As the lungs are maximally exposed to the proinflammatory cascade, receiving the entire cardiac output, they provide valuable insight into dynamic microcirculatory changes during systemic inflammation [17]. Consequently, bedside measurement of extravascular lung water index (EVLWI) performed by single transpulmonary thermodilution allows the estimation of the extent of capillary leak and fluid overload [11,18-23]. In this study, we investigated the prognostic value of EVLWI,

\section{SpringerOpen ${ }^{\circ}$}

(C) 2012 Cordemans et al.; licensee Springer This is an Open Access article distributed under the terms of the Creative Commons Attribution License (http://creativecommons.org/licenses/by/2.0), which permits unrestricted use, distribution, and reproduction in any medium, provided the original work is properly cited. 
capillary leak parameters, IAH, and fluid balance in critically ill patients.

\section{Methods \\ Patients}

We collected data from March 2004 to August 2007 in 123 patients treated in two ICU's in Ziekenhuis Netwerk Antwerpen (ZNA) Campus ZNA Stuivenberg, Antwerp, Belgium. Critically ill patients requiring mechanical ventilation (MV) and, according to clinical appraisal, extended hemodynamic monitoring by single transpulmonary thermodilution technique were consecutively included. Internal review board approval was obtained, and due to the non-interventional and retrospective nature of the study, the need for informed consent was waived (EC approval number 3765).

\section{Definitions}

Acute lung injury (ALI) and acute respiratory distress syndrome $(A R D S)$ were diagnosed according to international criteria [24].

EVLWI was recorded as the mean of two daily EVLWI measurements. EVLWI $I_{\min \text {,max,mean }}$ were the minimal, maximal, and mean EVLWI during ICU stay, respectively. Maximum EVLWI was measured on Daymax. $\Delta_{\max } E V L W I$ indicated the maximum difference between all EVLWI measurements during ICU stay and was computed in accordance with overall EVLWI trend $(\triangle E V L W I$ or the difference between the first and the last recorded EVLWI). If during ICU stay an increase of EVLWI was recorded followed by an equal EVLWI drop, $\Delta_{\max } E V L W I$ was given the sign of $\triangle E V L W I$. Patients with an EVLWI decrease of $>2 \mathrm{~mL} / \mathrm{kg}\left(\Delta_{\max }\right.$ EVLWI $<-2 \mathrm{~mL} / \mathrm{kg}$ ) and an overall drop in EVLWI during the first week of ICU admission (negative $\triangle E V L W I$ ) were called 'responders'.

Intra-abdominal pressure (IAP) was the mean of two daily IAP measurements. IAP $_{\max \text {, mean }}$ were the maximum and the mean IAP during ICU stay. IAH was defined as $\mathrm{IAP}_{\text {mean }} \geq 12 \mathrm{mmHg}$ and abdominal perfusion pressure (APP) as mean arterial pressure (MAP) minus IAP according to consensus definitions [15].

Daily fluid balance was calculated by subtracting the urinary output from the fluid intake (including both IV and enteral fluid administration); each day cumulative fluid balance was computed by the addition of daily fluid balances.

Capillary leak index (CLI) was defined as C-reactive protein (CRP) (milligrams per deciliter) over albumin (grams per liter) ratio, multiplied by 100 [25].

Conservative late fluid management (CLFM) was determined as even-to-negative fluid balance on at least two consecutive days during the first week of ICU stay
[12]. In this study, CLFM was used as a descriptive term and did not signify any study intervention.

\section{Data collection and methods}

For the entire duration of the ICU stay, relevant demographic, clinical, and laboratory data along with daily assessment of fluid balance, sequential organ failure assessment (SOFA) score [26], IAP, MV settings, and extended hemodynamic monitoring variables were registered in an electronic database, supplemented by mortality on day 28. Severity of illness on ICU admission was described by an averaged simplified acute physiology score [27] and acute physiology and chronic health evaluation score [28].

IAP was measured via a Foley bladder catheter as described previously [29], in the complete supine position and in stable conditions twice daily. In patients with IAH, the IAP was also continuously monitored via a balloon-tipped catheter placed in the stomach connected to the CiMON monitor (Pulsion Medical Systems, Munich, Germany).

A central venous catheter and a thermistor-tipped arterial thermodilution catheter (Pulsiocath 5F) inserted into the femoral artery and attached to a PiCCOplus ${ }^{\circledR}$ system (Pulsion Medical Systems, Munich, Germany) were already in place for each patient. Transpulmonary thermodilution measurements were obtained by central venous injection of three $20-\mathrm{mL}$ boluses of cooled saline $\left(<8^{\circ} \mathrm{C}\right)$. For each set of thermodilution determinations, the mean values were used for statistical analysis. Cardiac output (CO), global end diastolic volume (GEDV), extravascular lung water (EVLW), global ejection fraction (GEF), pulmonary vascular permeability index (PVPI), stroke volume variation, and pulse pressure variation were calculated using the PiCCOplus ${ }^{\circledR}[18]$. EVLW was indexed to body weight (EVLWI) and CO and GEDV to body surface area (cardiac index, GEDV index).

\section{Study design}

In this observational study, no protocol-directed intervention was performed; treatment was based on recent ICU guidelines. We analyzed process-of-care variables for the first 7 days of ICU admission. The primary outcome parameter was 28-day mortality. Secondary outcome parameters were organ dysfunction, duration of $\mathrm{MV}$, and achievement of CLFM.

\section{Statistical analysis}

The primary data analysis compared survivors to nonsurvivors according to 28-day mortality. Subsequently, patients were stratified by occurrence of IAH, achievement of CLFM, and responders vs nonresponders. 
Continuous data were expressed by mean \pm SD, and intergroup differences were determined by one-way analysis of variance (ANOVA) analyses day by day for 1 week. Categorical data were expressed as frequency distributions and/or percentages, and the $\chi^{2}$ test was used to determine intergroup differences. Two-sided $p$ values $<0.05$ were considered to indicate statistical significance.

Time course of CLI, total SOFA score, EVLWI, APP, daily, and cumulative fluid balance was described by clustered error bar graphs representing mean $\pm \mathrm{SE}$. Receiver-operating characteristic (ROC) curves were determined and optimal cutoffs for CLI, EVLWI, and $\Delta_{\max }$ EVLWI were derived, creating categorical data.

Stepwise multivariate logistic regression was performed to determine the independent risk factors for 28-day mortality and for not achieving CLFM. Risk factors significant at the 0.1 level in univariate analysis were included in the models. The Hosmer-Lemeshow test was used assessing the goodness of fit.

The Kaplan-Meier method was used to analyze differences in cumulative survival and duration of MV; distribution was compared using the log-rank test. We used SPSS software package (version 17.0.1; SPSS, Chicago, IL, USA) for data analysis.

\section{Results}

Patients

We included 123 predominantly medical $(n=109)$ patients on MV, of whom 65 (53\%) died after 28 days. At baseline, no significant differences were found between groups, as shown in Table 1, except for lower MAP and GEF in nonsurvivors.

\section{Process-of-care variables}

Figure 1 depicts process-of-care variables stratifying patients by survival.

CLI

CLI had a biphasic course with a maximum on day 3, which was significantly higher in patients not achieving CLFM (76.1 \pm 49.6 vs $53.2 \pm 45.6, p=0.017)$. ROC statistics for CLI on day 3 to predict no CLFM achievement revealed an area under the curve (AUC) of 0.658 and a derived cutoff point of $>61$ (sensitivity $62 \%$, specificity $68 \%$, and positive predictive value (PPV) $80 \%$ ).

\section{EVLWI}

EVLWI measurements are outlined in Table 2. ROC statistics using baseline EVLWI, EVLWI max $_{\text {, }}$, and EVLWImean to predict outcome revealed an AUC of 0.513, 0.591, and 0.595 , respectively. The best predictor for mortality was EVLWI $\max$ with a cutoff point of $>11 \mathrm{~mL} / \mathrm{kg}$, showing a $60 \%$ sensitivity and a $57 \%$ specificity with a PPV of $61 \% . \mathrm{EVLWI}_{\max }>11 \mathrm{~mL} / \mathrm{kg}$ was correlated with a higher percentage of ALI (70\% vs 34\%, $p<0.001)$, higher tidal volumes $(8.8 \pm 1.9$ vs $7.8 \pm 1.4 \mathrm{~mL} / \mathrm{kg}, p=0.001)$, and a trend to higher mortality ( $61 \%$ vs $44 \%, p=0.061)$. $\Delta_{\max }$ EVLWI was significantly lower if CLFM was achieved $(-2.4 \pm 4.8$ vs $1.0 \pm 5.5 \mathrm{~mL} / \mathrm{kg}, p=0.001)$ and in survivors (Table 2). The AUC for $\Delta_{\max } E V L W I$ to predict survival was 0.822 . The best cutoff point for $\Delta_{\max } E V L W I$ predicting good outcome was $<-2 \mathrm{~mL} / \mathrm{kg}$ showing a sensitivity of $74 \%$ and a specificity of $78 \%$ with a PPV of $75 \%$ (Figure 2).

\section{IAP measurements}

$\mathrm{IAP}_{\text {mean }}$ was lower if CLFM was achieved $(8.1 \pm 2.6$ vs $9.6 \pm 3.0 \mathrm{mmHg}, p=0.013$ ) and APP on day 3 was significantly higher in survivors $(80.7 \pm 10.7$ vs $70.9 \pm 13.5$ $\mathrm{mmHg}, p<0.001)$. IAH occurred in 25 patients $(20 \%)$ and was not correlated with 28-day mortality $(p=$ $0.658)$, CLFM achievement $(p=0.150)$, or whether patients were responders or not $(p=0.822)$. Pertinent variables recorded 1 week after ICU admission in the remaining 85 patients are summarized in Table 3.

\section{Cumulative fluid balance}

Cumulative fluid balance after 1 week was significantly lower in survivors $(4,970 \pm 7,737$ vs $9,502 \pm 6,909 \mathrm{~mL}$, $p=0.008)$, patients achieving CLFM $(1,056 \pm 7,047$ vs $10,282 \pm 5,788 \mathrm{~mL}, p<0.001)$, and responders $(3,567 \pm$ $7,984$ vs $10,021 \pm 5,920 \mathrm{~mL}, p<0.001)$ as shown in Figure 3.

\section{Total SOFA score}

Total SOFA score remained significantly lower on each day from day 2 in survivors, patients achieving CLFM, and responders $(p<0.001)$.

\section{Clinical outcomes}

Outcomes concerning organ function were described by the course of total SOFA score as above. Other major outcomes are shown in Table 4 and Kaplan-Meier plots are shown in Figure 4.

Mortality and duration of MV were lower in patients achieving CLFM and in responders. Responders had fewer days with cardiovascular, respiratory, liver, and coagulation failure during the first week of ICU admission.

Multivariate analysis identified that increasing $\mathrm{IAP}_{\text {mean }}$ and CLI on day 3 and being a nonresponder were independent risk factors for not achieving CLFM ( $p=0.919$ Hosmer-Lemeshow test) (Table 5). Increasing baseline creatinine and EVLWI $I_{\max }$, decreasing APP on day 3, not achieving CLFM, and being a nonresponder were independent risk factors for 28-day mortality $(p=0.808$ Hosmer-Lemeshow test) (Table 6).

\section{Discussion}

Our study demonstrated that a persistent increase in CLI, EVLWI, and fluid balance in critically ill patients is associated with poor outcome. We investigated the 
Table 1 Baseline characteristics

\begin{tabular}{|c|c|c|c|}
\hline Variable & Survivors $(n=58)$ & Nonsurvivors $(n=65)$ & $p$ value \\
\hline Age (years) & $63.2 \pm 14.2$ & $65.3 \pm 15.2$ & 0.436 \\
\hline Male sex (\%) & 66 & 67 & 0.798 \\
\hline BMI (kg/m2) & $26.6 \pm 6.6$ & $24.6 \pm 4.0$ & 0.053 \\
\hline Primary reason for MV (\%) & & & 0.937 \\
\hline Sepsis/septic shock & 24.1 & 24.7 & \\
\hline Pneumonia & 15.5 & 16.9 & \\
\hline ARDS & 13.7 & 10.8 & \\
\hline Postoperative/trauma & 5.4 & 6.1 & \\
\hline Acute COPD exacerbation & 6.9 & 7.7 & \\
\hline Congestive heart failure & 6.9 & 6.2 & \\
\hline Cardiac arrest & 5.2 & 6.2 & \\
\hline Hemorrhagic stroke & 8.6 & 7.6 & \\
\hline Other & 13.7 & 13.8 & \\
\hline Medical ICU (\%) & 40.7 & 48.0 & 0.562 \\
\hline ICU stay (day) & $31.8 \pm 18.1$ & $11.0 \pm 6.4$ & $<0.001$ \\
\hline \multicolumn{4}{|l|}{ Severity of disease } \\
\hline SAPS ॥ & $49.5 \pm 15.6$ & $53.9 \pm 18.1$ & 0.157 \\
\hline APACHE ॥ & $22.1 \pm 8.5$ & $23.0 \pm 10.7$ & 0.617 \\
\hline SOFA score at admission & $10.3 \pm 4.3$ & $10.4 \pm 4.5$ & 0.844 \\
\hline Acute lung injury (\%) & & & 0.836 \\
\hline Primary & 27.5 & 30.7 & \\
\hline Secondary & 25.8 & 21.5 & \\
\hline \multicolumn{4}{|l|}{ Organ function assessment } \\
\hline Number of organs failing & $2.2 \pm 1.3$ & $2.1 \pm 1.2$ & 0.605 \\
\hline \multicolumn{4}{|l|}{ Hemodynamic variables } \\
\hline $\mathrm{HR}(\mathrm{bpm})$ & $96.7 \pm 20.4$ & $98.6 \pm 18.8$ & 0.661 \\
\hline Mean arterial pressure $(\mathrm{mmHg})$ & $84.2 \pm 13.4$ & $78.7 \pm 10.4$ & 0.011 \\
\hline Met shock criteria (\%) & 69.0 & 69.2 & 0.975 \\
\hline Vasopressor use (\%) & 69.0 & 67.8 & 0.880 \\
\hline $\mathrm{Cl}\left(\mathrm{L} / \mathrm{min} / \mathrm{m}^{2}\right)$ & $3.6 \pm 1.1$ & $3.1 \pm 1.6$ & 0.255 \\
\hline SW (\%) & $11.8 \pm 7.1$ & $14.4 \pm 6.9$ & 0.236 \\
\hline GEF (\%) & $21.2 \pm 8.1$ & $15.1 \pm 7.7$ & 0.015 \\
\hline GEDVI $\left(\mathrm{mL} / \mathrm{m}^{2}\right)$ & $766.2 \pm 165.0$ & $725.6 \pm 174.5$ & 0.42 \\
\hline EVLWI (mL/kg) & $9.8 \pm 3.9$ & $10.5 \pm 5.2$ & 0.543 \\
\hline PVPI & $2.4 \pm 0.9$ & $2.4 \pm 1.1$ & 0.869 \\
\hline \multicolumn{4}{|l|}{ Respiratory variables } \\
\hline Tidal volume (mL/kg of PBW) & $8.2 \pm 1.7$ & $8.3 \pm 1.7$ & 0.709 \\
\hline Plateau pressure $\left(\mathrm{cmH}_{2} \mathrm{O}\right)$ & $23.8 \pm 6.5$ & $24.1 \pm 8.2$ & 0.792 \\
\hline PEEP $\left(\mathrm{cmH}_{2} \mathrm{O}\right)$ & $7.0 \pm 2.2$ & $6.2 \pm 2.3$ & 0.075 \\
\hline Dynamic compliance $\left(\mathrm{mL} / \mathrm{cmH}_{2} \mathrm{O}\right)$ & $40.9 \pm 15.6$ & $39.0 \pm 22.6$ & 0.635 \\
\hline $\mathrm{PaO}_{2} / \mathrm{FIO}_{2}$ & $263.4 \pm 135.1$ & $271.7 \pm 154.9$ & 0.755 \\
\hline \multicolumn{4}{|l|}{ Renal and metabolic variables } \\
\hline Creatinine (mg/dL) & $1.8 \pm 1.7$ & $2.5 \pm 2.9$ & 0.095 \\
\hline Urine output (mL/day) & $1,524.6 \pm 1,342.7$ & $1,428.5 \pm 1,236.6$ & 0.683 \\
\hline Albumin (mg/dL) & $25.0 \pm 7.5$ & $27.0 \pm 8.7$ & 0.194 \\
\hline $\mathrm{pH}$ & $7.35 \pm 0.11$ & $7.32 \pm 0.12$ & 0.205 \\
\hline \multicolumn{4}{|l|}{ Immune system } \\
\hline CRP $(\mathrm{mg} / \mathrm{dL})$ & $10.6 \pm 9.8$ & $13.8 \pm 12.4$ & 0.127 \\
\hline \multicolumn{4}{|l|}{ Central nervous system } \\
\hline Glasgow Coma Score & $8.1 \pm 5.1$ & $8.2 \pm 5.2$ & 0.905 \\
\hline
\end{tabular}


Table 1 Baseline characteristics (Continued)

\begin{tabular}{llll}
\hline Capillary leak index & $52.7 \pm 56.2$ & $61.8 \pm 61.3$ & 0.411 \\
\hline Intra-abdominal pressure $(\mathrm{mmHg})$ & $8.2 \pm 3.5$ & $7.9 \pm 3.7$ & 0.722 \\
\hline Abdominal perfusion pressure $(\mathrm{mmHg})$ & $75.4 \pm 13.9$ & $70.4 \pm 11.3$ & 0.071 \\
\hline Fluid balance $(\mathrm{mL} /$ day) & $1,755.9 \pm 4,616.0$ & $2,133.8 \pm 3,525.1$ & 0.612 \\
\hline
\end{tabular}

BMI, body mass index; MV, mechanical ventilation; ARDS, acute respiratory distress syndrome; COPD, chronic obstructive pulmonary disease; SAPS, simplified acute physiology score; APACHE, acute physiology and chronic health evaluation; SOFA, sequential organ failure assessment; HR, heart rate; Cl, cardiac index; SVV, stroke volume variation; GEF, global ejection fraction; GEDVI, global end-diastolic volume index; EVLWI, extravascular lung water index; PVPI, pulmonary vascular permeability index; PBW, predicted body weight; PEEP, positive end-expiratory pressure; CRP, C-reactive protein.

precise prognostic value of these parameters and were able to formulate a unifying hypothesis implementing concepts of earlier studies (Figure 5).

As early as 1942, Cuthbertson introduced the concept of a dual metabolic response to bodily injury [30]. In direct response to initial proinflammatory cytokines and stress hormones, the ebb phase represents a distributive shock characterized by arterial vasodilatation and transcapillary albumin leak [31] abating plasma oncotic pressure. Arterial underfilling, microcirculatory dysfunction, and secondary interstitial edema lead to systemic hypoperfusion and impaired regional tissue oxygenation [2]. In this early stage of shock, adequate fluid therapy comprises of goal-directed filling [3] to prevent evolution to multiple organ dysfunction syndrome (MODS). As compensatory neuroendocrine reflexes and potential renal dysfunction result in sodium and water retention [32], positive fluid balances are inherent in the ebb phase. Patients with higher severity of illness need more fluids to achieve cardiovascular optimization. Therefore, at this point, fluid balance may be considered a biomarker of critical illness [33].

Patients overcoming shock attain homeostasis inflammatory mediators within 3 days [1]. Subsequent hemodynamic stabilization and restoration of plasma oncotic pressure set off the flow phase with resumption of diuresis and mobilization of extravascular fluid resulting in negative fluid balances. In line with Murphy et al. [12], we found CLFM achievement to be a strong and independent predictor of survival. In contrast, patients with persistent systemic inflammation maintain capillary leak and do not reach the flow phase, accumulating further positive fluid balances. In this context, we introduce the global increased permeability syndrome (GIPS), characterized by nonresponders with increased CLI, no CLFM achievement, and progressing organ failure. GIPS represents a 'third hit' of shock following acute injury and MODS.

We defined CLI as a parameter of capillary leak, assuming that increased vascular permeability caused by systemic inflammation is associated with high CRP levels [34] and hypoalbuminemia [31]. CLI had a biphasic course and the maximum reached on the third day of shock was an independent predictor of CLFM achievement. Previously, a negative cumulative balance $[8,12,13,35,36]$ and lower PVPI [22] on day 3 were correlated with better survival. The third day of shock seems to be a crucial turning point [37] at which homeostasis of cytokines is accompanied by the healing of microcirculatory disruptions and 'closure' of the capillary leak. This interpretation is supported by Boerma et al. who demonstrated normalization of the microcirculatory blood flow on day 3 in septic patients [38].

As a result of capillary leak and an impaired flow phase, overzealous administration of fluids in GIPS will lead to gross fluid overload and tissue edema [14]. Interstitial edema raises the pressure in all four major body compartments: head, chest, abdomen, and extremities. Consequently, venous resistance of organs within compartments increases and perfusion pressure decreases contributing to progression of organ failure. As different compartments interact and reciprocally transmit compartment pressures, the concept of polycompartment syndrome is suggested [39].

The abdomen plays a central role in GIPS and polycompartment syndrome. Positive cumulative fluid balance is a known risk factor for secondary IAH [40] which in turn is associated with renal dysfunction [41]. Therefore, fluid overload leading to IAH and renal dysfunction may counteract its own resolution. Data from our study support these ideas, demonstrating higher average positive cumulative fluid balance and renal SOFA score after 1 week in patients developing IAH. Moreover, we determined increased IAP $_{\text {mean }}$ as an independent risk factor for no CLFM achievement and decreased APP as risk factor for 28-day mortality.

As the adverse effects of fluid overload in states of capillary leak are particularly pronounced in the lungs [17], monitoring EVLWI may offer a valuable tool to guide fluid management in the critically ill. In line with previous reports, we established a correlation between EVLWI $_{\text {max }}$ during admission and poor outcome [42]. An increased EVLWI max may indicate a state of capillary leak, associated with a higher severity of illness and mortality $[11,22,23,42]$. In this context, data from Sturm et al. are particularly of interest, correlating EVLWI with albumin extravasation in patients after multiple trauma [43]. 
Panel A: Capillary Leak Index

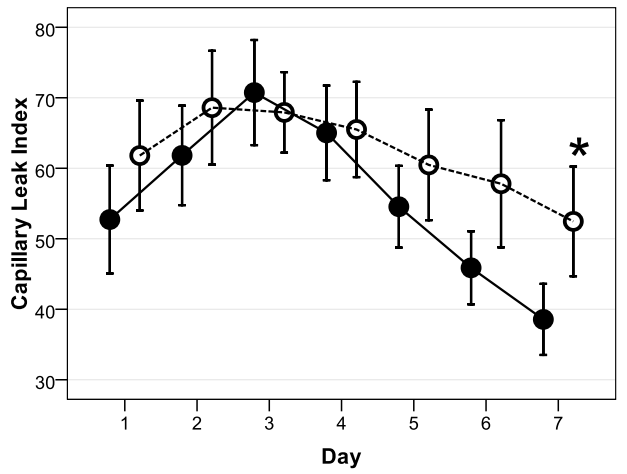

Panel C: Extravascular Lung Water

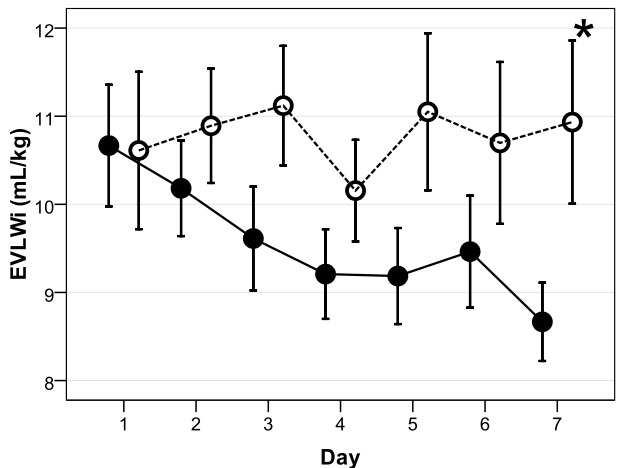

Panel E: Daily Fluid Balance

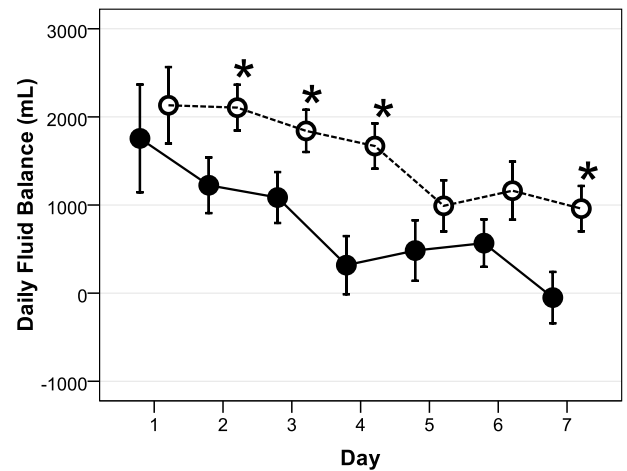

Panel B: Total SOFA-score

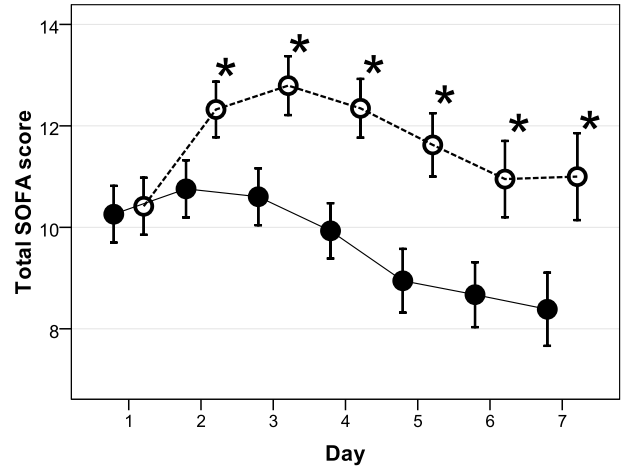

Panel D: Abdominal Perfusion Pressure

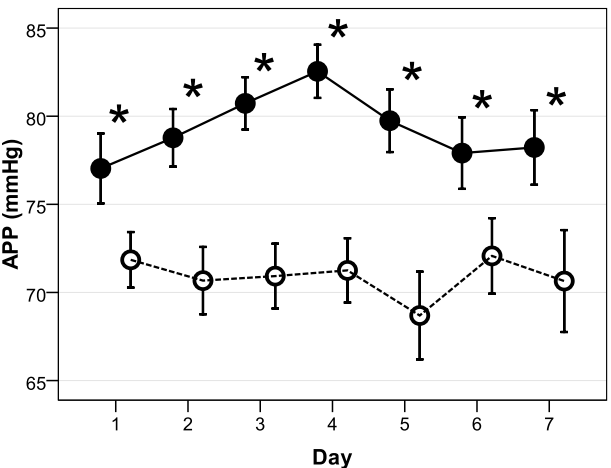

Panel F: Cumulative Fluid Balance

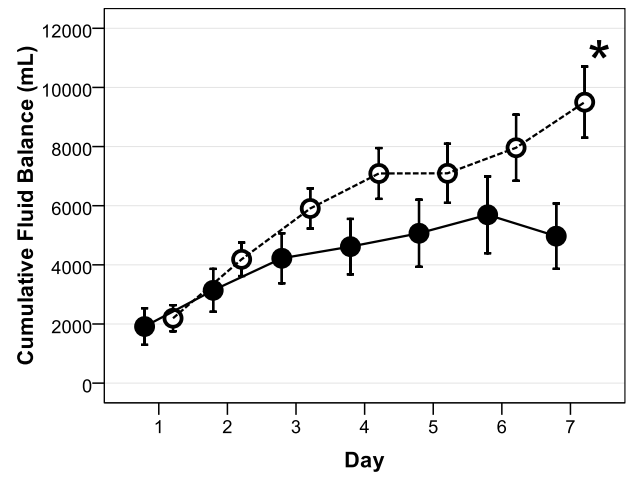

Figure 1 Time course of main variables. Mean \pm standard error of pertinent variables for the first week after ICU admission. Survivors are depicted by a full line and nonsurvivors by a dotted line. ${ }^{*} p<0.05$, day-by-day pairwise compared between survivors and nonsurvivors (oneway ANOVA).

The course of EVLWI during the first week of admission may even be a better outcome predictor. Responders, defined as patients with an EVLWI decrease of $>2$
$\mathrm{mL} / \mathrm{kg}$, were more likely to achieve CLFM, had more organ-failure-free and ventilator-free days, and a better 28 -day outcome. These data suggest that responders 
Table 2 Analysis of EVLWI

\begin{tabular}{llll}
\hline Variable & $\begin{array}{l}\text { Survivors }(\boldsymbol{n}= \\
\mathbf{5 8})\end{array}$ & $\begin{array}{l}\text { Nonsurvivors }(\boldsymbol{n}= \\
\mathbf{6 5})\end{array}$ & $\begin{array}{l}\boldsymbol{p} \\
\text { value }\end{array}$ \\
\hline $\mathrm{EVLWI}_{\min }(\mathrm{mL} / \mathrm{kg})$ & $7.3 \pm 2.7$ & $8.5 \pm 4.1$ & 0.059 \\
$\mathrm{EVLWI}_{\text {max }}(\mathrm{mL} / \mathrm{kg})$ & $11.7 \pm 4.3$ & $13.7 \pm 5.9$ & 0.041 \\
$\mathrm{EVLWI}_{\text {mean }}(\mathrm{mL} /$ & $9.2 \pm 3.3$ & $10.7 \pm 4.6$ & 0.043 \\
$\mathrm{~kg})$ & & & \\
$\begin{array}{l}D \text { ay } \\
(\text { day })\end{array}$ & $2.4 \pm 1.4$ & $3.1 \pm 2.2$ & 0.026 \\
$\begin{array}{l}\Delta E V L W I \\
\Delta_{\text {max }} \mathrm{EVLWI}(\mathrm{mL} / \mathrm{kg})\end{array}$ & $-1.3 \pm 3.5$ & $2.1 \pm 5.0$ & \\
$\mathrm{~kg})$ & $-3.3 \pm 3.8$ & $2.5 \pm 5.3$ & $<0.001$ \\
\hline
\end{tabular}

EVLWI $I_{\text {min }}$ minimal EVLWI during ICU stay; $E V L W I_{\max }$ maximal EVLWI during ICU stay; EVLWI mean, mean EVLWI during ICU stay; $\triangle E V L W I$, difference between first and last extravascular lung water index; $\Delta_{\max } E V L W l$, maximal difference between extravascular lung water index.

overcome the distributive shock and make a transition to the flow phase. Nonresponders on the other hand stay in the grip of the ebb phase and progress to GIPS associated with interstitial fluid accumulation, organ failure, and death. In this hypothesis, (the change in) EVLWI has a prognostic value as a reflection of the extent of capillary leak rather than as a quantification of lung function impairment. Indeed, the degree of hypoxemia in ARDS is an inferior prognostic factor, as extrapulmonary organ failure mostly determines outcome [44]. Accordingly, in a subgroup analysis of patients with ARDS, Sakka et al. found no higher maximum EVLWI in nonsurvivors [42]. Therefore, in an established state of capillary leak, time-dependent changes in EVLWI appear to be of superior value.

Our observations may have direct consequences on fluid management in the critically ill. Patients at risk for GIPS require restrictive fluid strategies and even fluid removal to avoid interstitial edema formation.

Our study has several important limitations. First, the observational nature of this study does not allow discrimination between a primary and secondary effect of fluid balance on outcome; prospective trials are warranted to determine if fluid overload is cause or

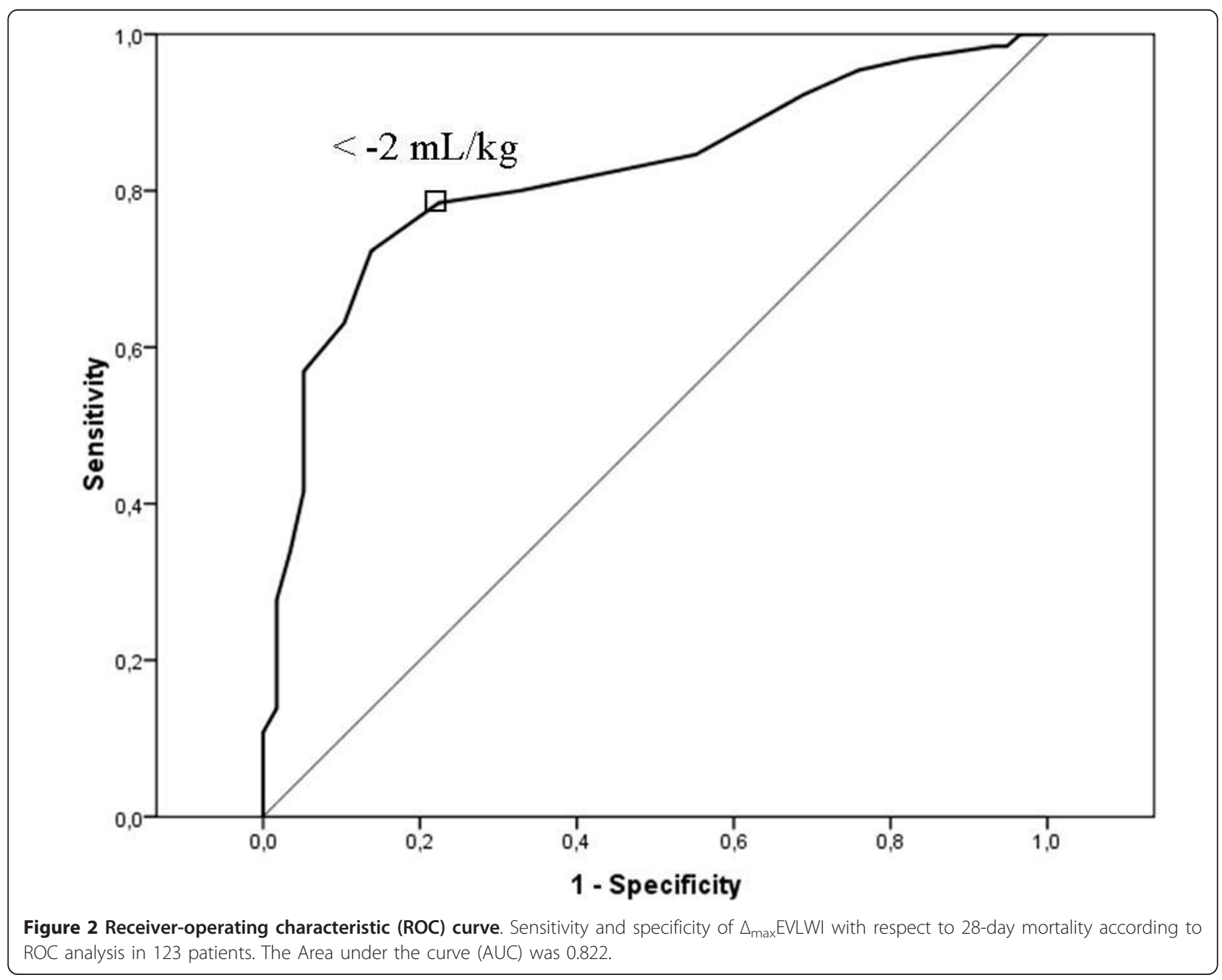


Table 3 Analysis by IAH

\begin{tabular}{|c|c|c|c|}
\hline Variable (1 week after ICU admission) & No IAH $(n=64)$ & $\mathrm{IAH}(n=21)$ & $p$ value \\
\hline \multicolumn{4}{|l|}{ SOFA score } \\
\hline Respiratory & $1.5 \pm 1.5$ & $1.7 \pm 1.8$ & 0.374 \\
\hline Nervous & $2.4 \pm 1.6$ & $3.5 \pm 1.0$ & 0.004 \\
\hline Cardiovascular & $2.0 \pm 1.6$ & $2.7 \pm 1.3$ & 0.092 \\
\hline Liver & $0.6 \pm 1.0$ & $1.2 \pm 1.4$ & 0.038 \\
\hline Coagulation & $0.8 \pm 1.1$ & $1.3 \pm 1.1$ & 0.084 \\
\hline Renal & $1.1 \pm 1.5$ & $2.4 \pm 1.8$ & 0.002 \\
\hline Total & $8.3 \pm 4.9$ & $12.8 \pm 4.9$ & 0.001 \\
\hline \multicolumn{4}{|l|}{ Respiratory variables } \\
\hline Tidal volume (mL/kg of PBW) & $8.9 \pm 2$ & $8.4 \pm 2.3$ & 0.343 \\
\hline Plateau pressure $\left(\mathrm{cmH}_{2} \mathrm{O}\right)$ & $24.4 \pm 6.9$ & $29.1 \pm 6$ & 0.010 \\
\hline PEEP $\left(\mathrm{cmH}_{2} \mathrm{O}\right)$ & $7.3 \pm 2.9$ & $10.2 \pm 3.7$ & 0.001 \\
\hline Dynamic compliance $\left(\mathrm{mL} / \mathrm{cmH}_{2} \mathrm{O}\right)$ & $43.9 \pm 24.2$ & $38.4 \pm 13$ & 0.353 \\
\hline $\mathrm{PaO}_{2} / \mathrm{FIO}_{2}$ & $275.7 \pm 98.4$ & $257.8 \pm 106.2$ & 0.486 \\
\hline Ventilator-free days & $2.1 \pm 2.1$ & $1.4 \pm 2.1$ & 0.479 \\
\hline Cumulative fluid balance $(\mathrm{mL})$ & $5,943 \pm 7,125$ & $10,176 \pm 7,523$ & 0.024 \\
\hline EVLWI (mL/kg) & $9.8 \pm 4.3$ & $9.2 \pm 3.7$ & 0.592 \\
\hline
\end{tabular}

IAH, intra-abdominal hypertension; SOFA, sequential organ failure assessment; PBW, predicted body weight; PEEP, positive end-expiratory pressure; EVLWI, extravascular lung water index.

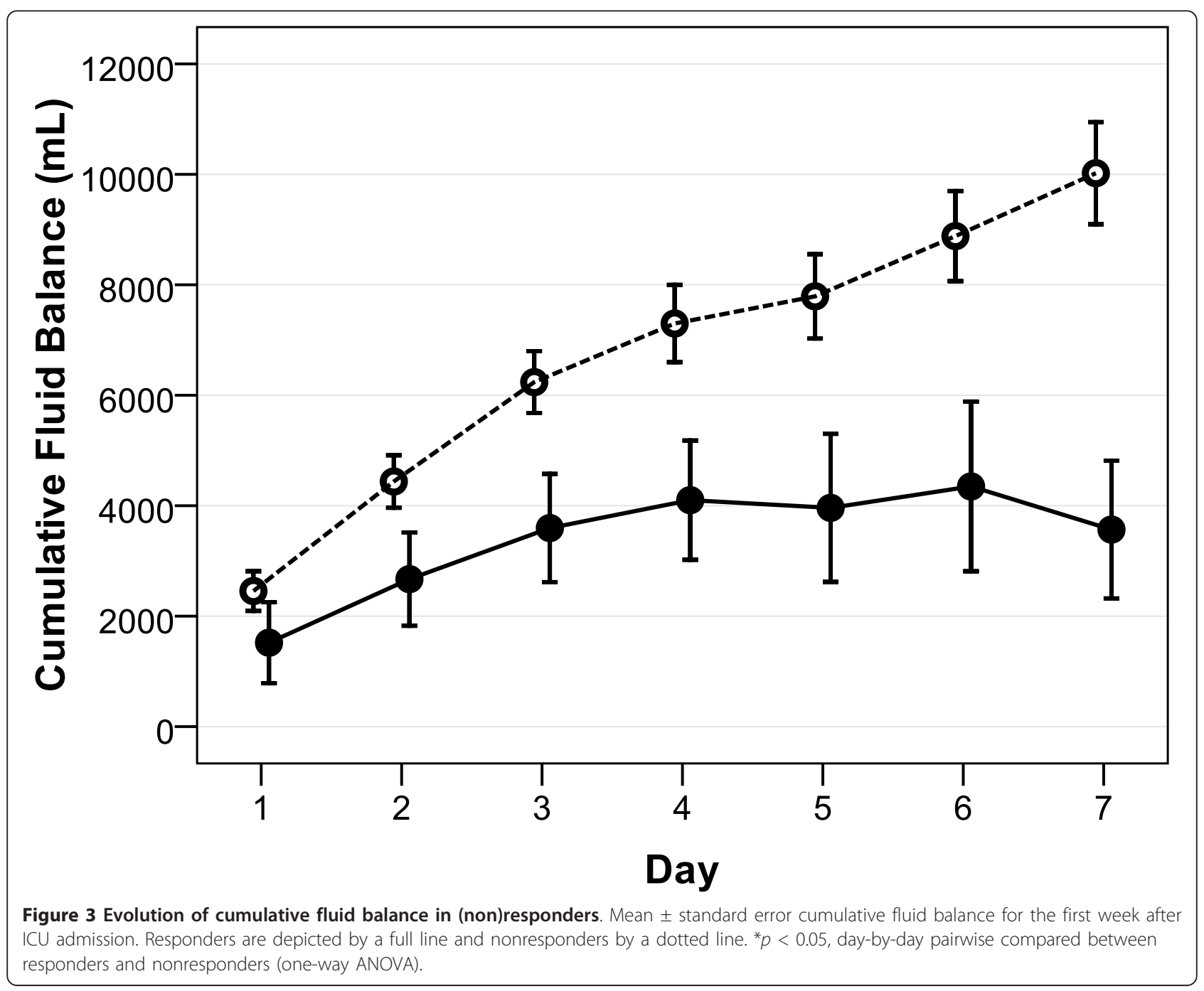




\begin{tabular}{|c|c|c|c|c|c|}
\hline & & & Responder $(n=52)$ & Nonresponder $(n=71)$ & $p$ value \\
\hline \multirow[t]{7}{*}{ First week } & Organ-failure-free days & Respiratory & $5.5 \pm 1.9$ & $3.9 \pm 2.4$ & $<0.001$ \\
\hline & & Nervous & $2.1 \pm 2.6$ & $1.7 \pm 2.2$ & 0.454 \\
\hline & & Cardiovascular & $3.4 \pm 2.7$ & $1.4 \pm 2.1$ & $<0.001$ \\
\hline & & Liver & $6.1 \pm 1.9$ & $5.3 \pm 2.3$ & 0.046 \\
\hline & & Coagulation & $5.9 \pm 2.1$ & $5.0 \pm 2.4$ & 0.031 \\
\hline & & Renal & $4.8 \pm 2.7$ & $3.9 \pm 2.7$ & 0.063 \\
\hline & Ventilator-free days & & $2.5 \pm 2.3$ & $1.5 \pm 2.3$ & 0.023 \\
\hline First 28 days & Death (\%) & & 25.0 & 73.2 & $<0.001$ \\
\hline
\end{tabular}

Panel A: Survival (CLFM)

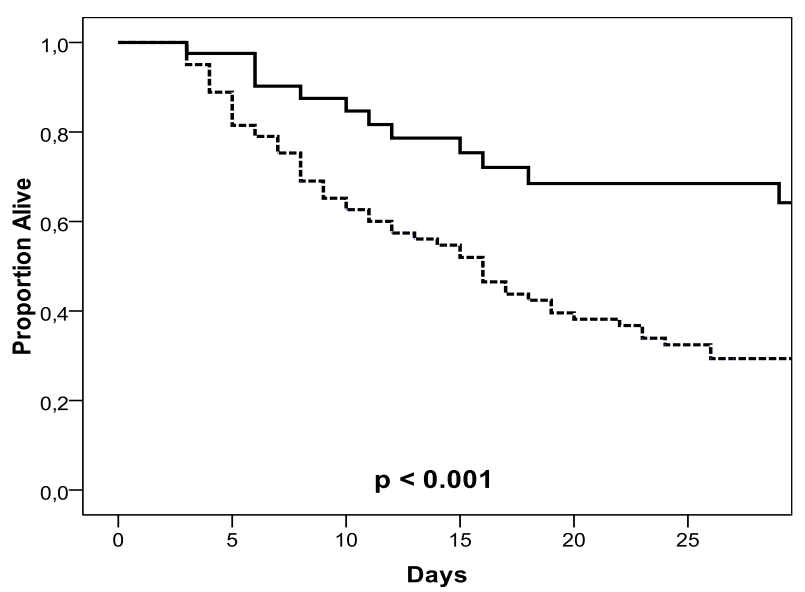

Panel C: Survival (responder)

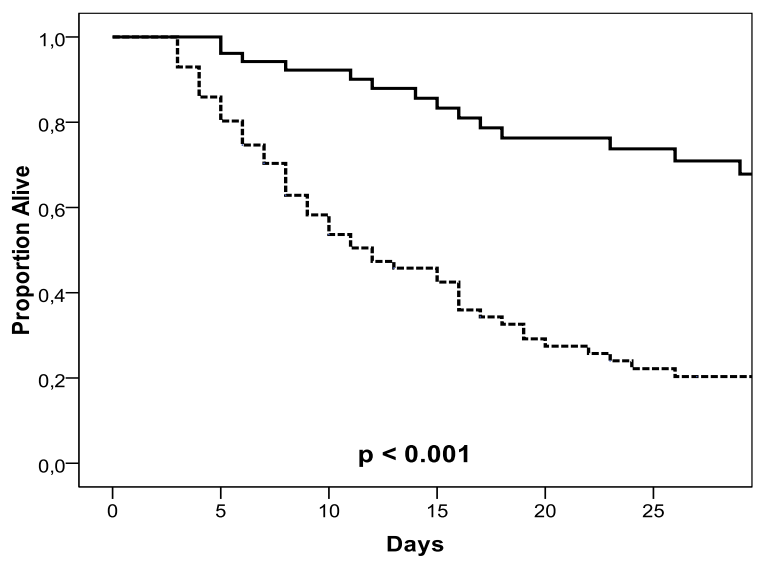

Panel B: Ventilation (CLFM)

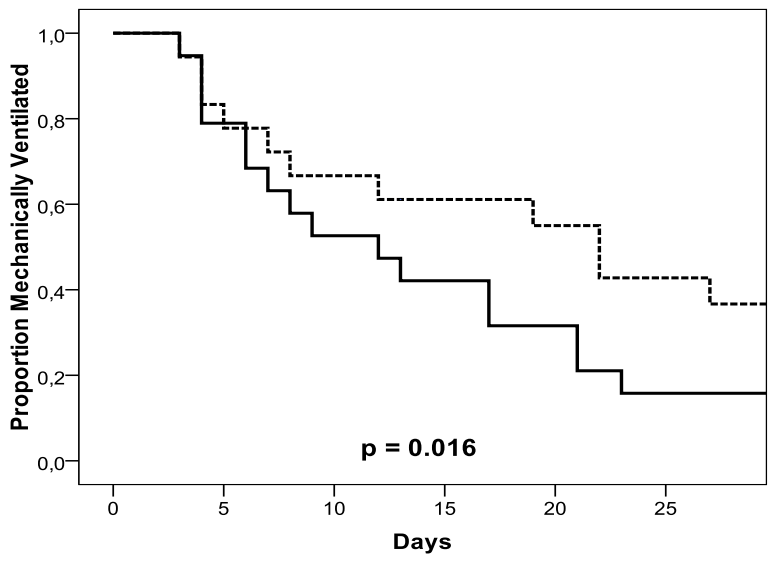

Panel D: Ventilation (responder)

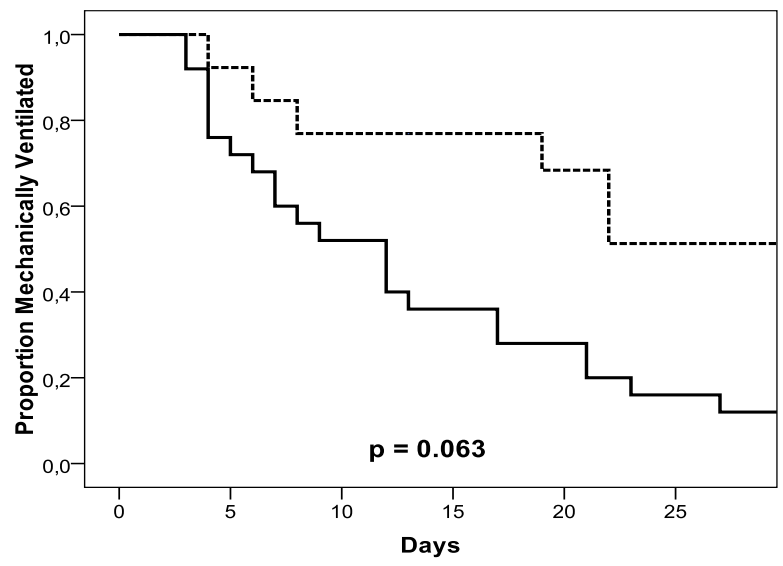

Figure 4 Kaplan-Meier plots. Kaplan-Meier plots for cumulative survival and proportion of patients on MV. We compared CLFM and no CLFM achievement (full lines and dotted lines, respectively) in A (survival) and B (ventilation). In C (survival) and D (ventilation), responders and nonresponders were compared (full lines and dotted lines, respectively). 
Table 5 Multivariate analysis of independent risk factors for not achieving CLFM

\begin{tabular}{lllll}
\hline & Variable & Adjusted OR & $\mathbf{9 5 \%} \mathrm{Cl}$ & $\boldsymbol{p}$ value \\
\hline Baseline & Age (years) & 1.00 & $0.97-1.03$ & 0.832 \\
& $\mathrm{BMI}\left(\mathrm{kg} / \mathrm{m}^{2}\right)$ & 0.93 & $0.85-1.01$ & 0.073 \\
\hline Day 3 & Total SOFA score & 1.03 & $0.92-1.16$ & 0.575 \\
& $\mathrm{CLI}>61$ & 2.76 & $1.02-7.48$ & 0.046 \\
\hline ICU stay & IAP & 1.28 & $1.06-1.54$ & 0.011 \\
& Nonresponder & 5.52 & $2.01-15.15$ & 0.001 \\
\hline
\end{tabular}

$\mathrm{OR}$, odds ratio; $\mathrm{Cl}$, confidence interval; $\mathrm{BMI}$, body mass index; $\mathrm{CLI}$, capillary leak index; IAP, intra-abdominal pressure.

Table 6 Multivariate analysis of independent risk factors for 28-day mortality

\begin{tabular}{lllll}
\hline & Variable & Adjusted OR & $\mathbf{9 5 \%} \mathrm{Cl}$ & $\boldsymbol{p}$ value \\
\hline Baseline & Age (years) & 1.01 & $0.96-1.05$ & 0.801 \\
& BMI $\left(\mathrm{kg} / \mathrm{m}^{2}\right)$ & 0.92 & $0.83-1.03$ & 0.142 \\
& Creatinine $(\mathrm{mg} / \mathrm{dL})$ & 1.89 & $1.03-3.48$ & 0.041 \\
\hline Day 3 & APP $($ per $-10 \mathrm{mmHg})$ & 2.20 & $1.25-3.89$ & 0.007 \\
& Total SOFA score & 1.01 & $0.89-1.15$ & 0.852 \\
\hline ICU stay & EVLWI ${ }_{\text {max }}>11 \mathrm{~mL} / \mathrm{kg}$ & 4.57 & $1.32-15.63$ & 0.016 \\
& CLFM not achieved & 9.34 & $2.39-36.93$ & 0.001 \\
& Nonresponder & 7.14 & $2.23-22.91$ & 0.001 \\
\hline
\end{tabular}

OR, odds ratio; $\mathrm{Cl}$, confidence interval; BMI, body mass index; APP, abdominal perfusion pressure; SOFA, sequential organ failure assessment; $\mathrm{EVLWI}_{\text {max }}$ maximal EVLWI during ICU stay; CLFM, conservative late fluid management.

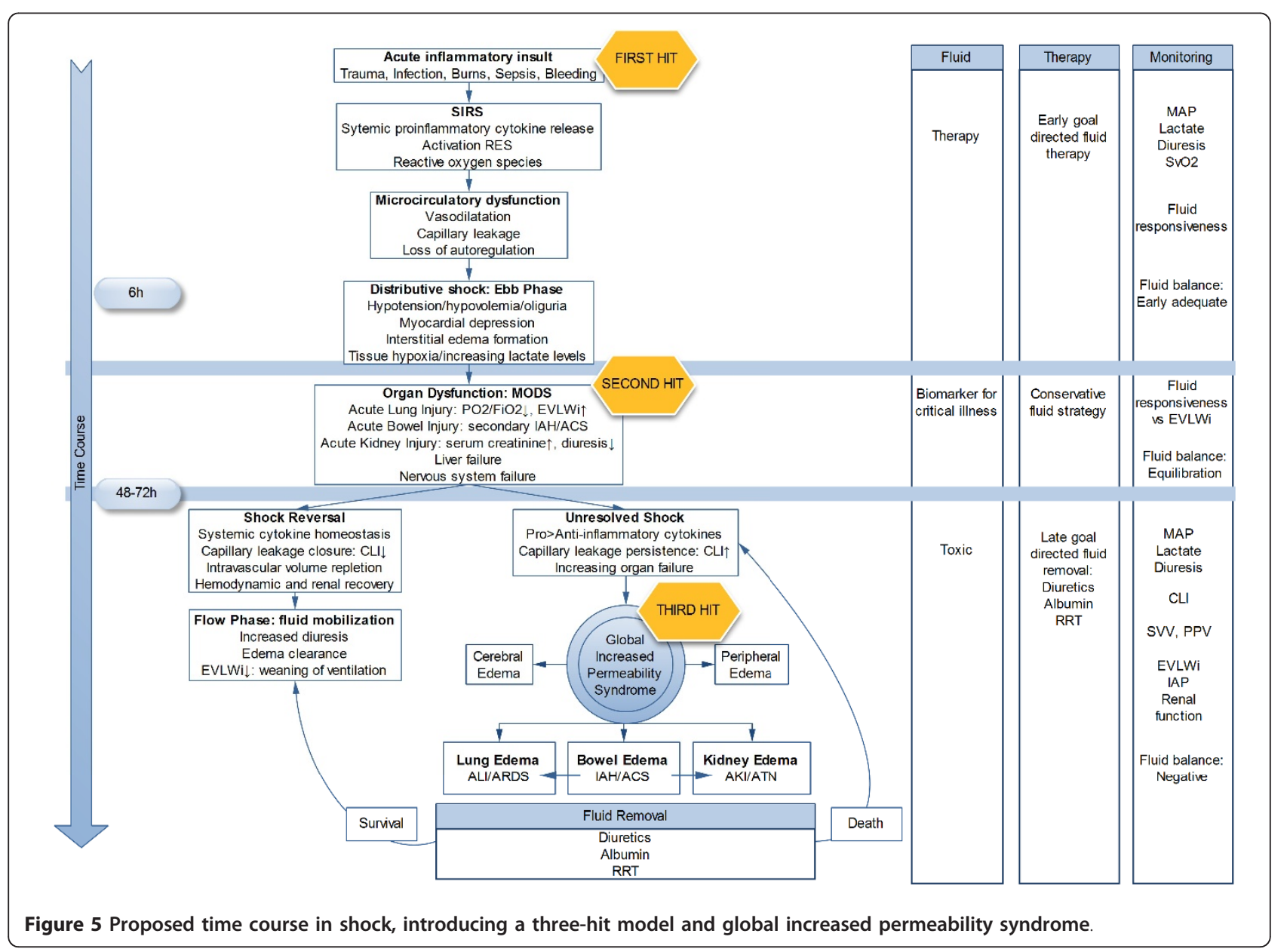


consequence of worse outcome. Second, inclusion of patients was based on clinical appraisal of the need of MV and thermodilution catheter monitoring. Therefore, the studied population was a specific case mix of seriously ill patients selected without well-defined objective rules making simple extrapolation of our results to a general ICU population impossible. However, albeit in this particular population, our observations contributed to some basic ideas regarding fluid management in patients with capillary leak as proposed in earlier reports $[1,14,16,37,40]$ and raised questions that should be addressed in future prospective investigations. Third, our database did not supply detailed information on the amounts of fluids administrated specified for the first 6 h. Early fluid resuscitation has an important impact on outcome $[12,45]$. There were no data on the type of fluids and infusion rates used during ICU stay either. Fourth, differences in MAP and GEF at baseline may be important confounding factors as they may reflect different hemodynamic states dictating whether a patient can mobilize fluids in the flow phase.

\section{Conclusions}

We identified a subgroup of mechanically ventilated patients with persistent capillary leak failing to reach the flow phase. In these patients, GIPS may reflect a third hit' and superfluous fluid administration may be considered toxic. Future prospective clinical trials evaluating any therapy aimed at a reduction of EVLWI are warranted.

\begin{abstract}
Abbreviations
ALI: acute lung injury; APP: abdominal perfusion pressure; AUC: area under the curve; CLFM: conservative late fluid management; CLI: capillary leak index; CO: cardiac output; Daymax: day on which maximal EVLWI was measured; EVLW(I): extravascular lung water (index); $\triangle E V L W I$ : difference between first and last extravascular lung water index; $\Delta_{\max } E V L W I$ : maximal difference between extravascular lung water index; GEDV(I): global enddiastolic volume (index); GEF: global ejection fraction; GIPS: global increased permeability syndrome; IAH: intra-abdominal hypertension; IAP: intraabdominal pressure; ICU: intensive care unit; MAP: mean arterial pressure; MV: mechanically ventilated; PPV: positive predictive value; PVPI: pulmonary vascular permeability index; ROC: receiver-operating characteristics; SOFA: sequential organ failure assessment; vs: versus.
\end{abstract}

\section{Acknowledgements}

The authors are indebted to Dr. Greg Martin and Ms. Harriet Adamson for their advice and technical assistance with the preparation of this manuscript. The authors also wish to thank the study nurses Ms. Anita Jans and Ms. Kim Serneels (ICU, ZNA Stuivenberg, Antwerp, Belgium) for their fantastic work in keeping the database up-to-date.

The study is supported by the Council of Internal Medicine (head Prof Dr Pierre Zachée, MD, PhD), ZNA Stuivenberg Hospital, who paid for the open access publication fee.

This article has been published as part of Annals of Intensive Care Volume 2 Supplement 1, 2012: Diagnosis and management of intra-abdominal hypertension and abdominal compartment syndrome. The full contents of the supplement are available online at http://www.annalsofintensivecare. com/supplements/2/S1

\section{Author details}

'Department of Intensive Care, Ziekenhuis Netwerk Antwerpen, Campus ZNA Stuivenberg, Lange Beeldekensstraat 267, 2060 Antwerpen 6, Belgium. ${ }^{2}$ II. Medizinische Klinik, Klinikum Rechts der Isar, Technische Universität München, Munich, Germany.

\section{Authors' contributions}

$C C, I D L, N V R, K S, H D$, and MM planned the study and were responsible for the design, coordination, and drafting the manuscript. WH participated in the study design and helped to draft the manuscript. CC and MM performed the statistical analysis and helped to draft the manuscript. All authors read and approved the final manuscript.

\section{Competing interests}

$\mathrm{WH}$ and MM are members of the medical advisory board of Pulsion Medical Systems (Munich, Germany), a monitoring company. The other authors declare that they have no competing interests.

Published: 5 July 2012

\section{References}

1. Bone RC: Immunologic dissonance: a continuing evolution in our understanding of the systemic inflammatory response syndrome (SIRS) and the multiple organ dysfunction syndrome (MODS). Annals of internal medicine 1996, 125(8):680-687.

2. Elbers PW, Ince C: Mechanisms of critical illness - classifying microcirculatory flow abnormalities in distributive shock. Critical care 2006, 10(4):221.

3. Rivers E, Nguyen B, Havstad S, Ressler J, Muzzin A, Knoblich B, Peterson E, Tomlanovich M: Early goal-directed therapy in the treatment of severe sepsis and septic shock. The New England journal of medicine 2001, 345(19):1368-1377.

4. Guyton AC: Interstitial fluid pressure. II. Pressure-volume curves of interstitial space. Circulation research 1965, 16:452-460.

5. Staub NC: The pathogenesis of pulmonary edema. Progress in cardiovascular diseases 1980, 23(1):53-80.

6. Humphrey H, Hall J, Sznajder I, Silverstein M, Wood L: Improved survival in ARDS patients associated with a reduction in pulmonary capillary wedge pressure. Chest 1990, 97(5):1176-1180.

7. Lowell JA, Schifferdecker C, Driscoll DF, Benotti PN, Bistrian BR: Postoperative fluid overload: not a benign problem. Critical care medicine 1990, 18(7):728-733.

8. Alsous F, Khamiees M, DeGirolamo A, Amoateng-Adjepong Y, Manthous CA: Negative fluid balance predicts survival in patients with septic shock: a retrospective pilot study. Chest 2000, 117(6):1749-1754.

9. Vincent JL, Sakr Y, Sprung CL, Ranieri VM, Reinhart K, Gerlach H, Moreno R, Carlet J, Le Gall JR, Payen D: Sepsis in European intensive care units: results of the SOAP study. Critical care medicine 2006, 34(2):344-353.

10. Brandstrup B, Tonnesen H, Beier-Holgersen R, Hjortso E, Ording H, LindorffLarsen K, Rasmussen MS, Lanng C, Wallin L, Iversen LH, Gramkow CS, Okholm M, Blemmer T, Svendsen PE, Rottensten HH, Thage B, Riis J, Jeppesen IS, Teilum D, Christensen AM, Graungaard B, Pott F, Danish Study Group on Perioperative Fluid Therapy: Effects of intravenous fluid restriction on postoperative complications: comparison of two perioperative fluid regimens: a randomized assessor-blinded multicenter trial. Annals of surgery 2003, 238(5):641-648.

11. Schuller D, Mitchell JP, Calandrino FS, Schuster DP: Fluid balance during pulmonary edema. Is fluid gain a marker or a cause of poor outcome? Chest 1991, 100(4):1068-1075.

12. Murphy CV, Schramm GE, Doherty JA, Reichley RM, Gajic O, Afessa B, Micek ST, Kollef MH: The importance of fluid management in acute lung injury secondary to septic shock. Chest 2009, 136(1):102-109.

13. Sakr Y, Vincent JL, Reinhart K, Groeneveld J, Michalopoulos A, Sprung CL, Artigas A, Ranieri VM: High tidal volume and positive fluid balance are associated with worse outcome in acute lung injury. Chest 2005, 128(5):3098-3108.

14. Prowle JR, Echeverri JE, Ligabo EV, Ronco C, Bellomo R: Fluid balance and acute kidney injury. Nature reviews 2010, 6(2):107-115.

15. Malbrain ML, Cheatham ML, Kirkpatrick A, Sugrue M, Parr M, De Waele J, Balogh Z, Leppaniemi A, Olvera C, Ivatury R, D'Amours S, Wendon J, 
Hillman K, Johansson K, Kolkman K, Wilmer A: Results from the International Conference of Experts on Intra-abdominal Hypertension and Abdominal Compartment Syndrome. I. Definitions. Intensive care medicine 2006, 32(11):1722-1732.

16. Wiedemann HP, Wheeler AP, Bernard GR, Thompson BT, Hayden D, deBoisblanc B, Connors AF Jr, Hite RD, Harabin AL: Comparison of two fluid-management strategies in acute lung injury. The New England journal of medicine 2006, 354(24):2564-2575.

17. Schrier RW, Wang W: Acute renal failure and sepsis. The New England journal of medicine 2004, 351(2):159-169.

18. Sakka SG, Ruhl CC, Pfeiffer UJ, Beale R, McLuckie A, Reinhart K, MeierHellmann A: Assessment of cardiac preload and extravascular lung water by single transpulmonary thermodilution. Intensive care medicine 2000, 26(2):180-187

19. Fernandez-Mondejar E, Guerrero-Lopez F, Colmenero M: How important is the measurement of extravascular lung water? Current opinion in critical care 2007, 13(1):79-83.

20. Berkowitz DM, Danai PA, Eaton S, Moss M, Martin GS: Accurate characterization of extravascular lung water in acute respiratory distress syndrome. Critical care medicine 2008, 36(6):1803-1809.

21. Monnet X, Anguel N, Osman D, Hamzaoui O, Richard C, Teboul JL: Assessing pulmonary permeability by transpulmonary thermodilution allows differentiation of hydrostatic pulmonary edema from ALI/ARDS. Intensive care medicine 2007, 33(3):448-453.

22. Kuzkov W, Kirov MY, Sovershaev MA, Kuklin VN, Suborov EV, Waerhaug K, Bjertnaes $L$ : Extravascular lung water determined with single transpulmonary thermodilution correlates with the severity of sepsisinduced acute lung injury. Critical care medicine 2006, 34(6):1647-1653.

23. Phillips CR, Chesnutt MS, Smith SM: Extravascular lung water in sepsisassociated acute respiratory distress syndrome: indexing with predicted body weight improves correlation with severity of illness and survival. Critical care medicine 2008, 36(1):69-73.

24. Bernard GR, Artigas A, Brigham KL, Carlet J, Falke K, Hudson L, Lamy M, Legall JR, Morris A, Spragg R: The American-European Consensus Conference on ARDS. Definitions, mechanisms, relevant outcomes, and clinical trial coordination. American journal of respiratory and critical care medicine 1994, 149(3 Pt 1):818-824.

25. Malbrain ML, Debaveye Y, De Coninck J, Delmarcelle D: Capillary leakage index as outcome predictor? Intensive Care Med 2001, 27:S229, (abstract).

26. Vincent $J L$, de Mendonca A, Cantraine F, Moreno R, Takala J, Suter PM, Sprung CL, Colardyn F, Blecher S: Use of the SOFA score to assess the incidence of organ dysfunction/failure in intensive care units: results of a multicenter, prospective study. Working group on "sepsis-related problems" of the European Society of Intensive Care Medicine. Critical care medicine 1998, 26(11):1793-1800.

27. Le Gall JR, Lemeshow S, Saulnier F: A new Simplified Acute Physiology Score (SAPS II) based on a European/North American multicenter study. Jama 1993, 270(24):2957-2963.

28. Knaus WA, Draper EA, Wagner DP, Zimmerman JE: APACHE II: a severity of disease classification system. Critical care medicine 1985, 13(10):818-829.

29. Malbrain ML: Different techniques to measure intra-abdominal pressure (IAP): time for a critical re-appraisal. Intensive care medicine 2004, 30(3):357-371

30. Cuthbertson DP: Post-shock metabolic response. Lancet 1942, i: 433-447

31. Fleck A, Raines G, Hawker F, Trotter J, Wallace PI, Ledingham IM, Calman KC: Increased vascular permeability: a major cause of hypoalbuminaemia in disease and injury. Lancet 1985, 1(8432):781-784.

32. Schrier RW: Body fluid volume regulation in health and disease: a unifying hypothesis. Annals of internal medicine 1990, 113(2):155-159.

33. Bagshaw SM, Brophy PD, Cruz D, Ronco C: Fluid balance as a biomarker: impact of fluid overload on outcome in critically ill patients with acute kidney injury. Critical care 2008, 12(4):169.

34. Pepys MB, Hirschfield GM: C-reactive protein: a critical update. The Journal of clinical investigation 2003, 111(12):1805-1812.

35. Simmons RS, Berdine GG, Seidenfeld JJ, Prihoda TJ, Harris GD, Smith JD, Gilbert TJ, Mota E, Johanson WG Jr: Fluid balance and the adult respiratory distress syndrome. The American review of respiratory disease 1987, 135(4):924-929.

36. Rosenberg $A L$, Dechert RE, Park PK, Bartlett RH: Review of a large clinical series: association of cumulative fluid balance on outcome in acute lung injury: a retrospective review of the ARDSnet tidal volume study cohort. Journal of intensive care medicine 2009, 24(1):35-46.

37. Rivers EP: Fluid-management strategies in acute lung injury - liberal, conservative, or both? The New England journal of medicine 2006, 354(24):2598-2600

38. Boerma EC, van der Voort PH, Spronk PE, Ince C: Relationship between sublingual and intestinal microcirculatory perfusion in patients with abdominal sepsis. Critical care medicine 2007, 35(4):1055-1060.

39. Malbrain ML, Wilmer A: The polycompartment syndrome: towards an understanding of the interactions between different compartments! Intensive care medicine 2007, 33(11):1869-1872

40. Malbrain ML, Chiumello D, Pelosi P, Bihari D, Innes R, Ranieri VM, Del Turco M, Wilmer A, Brienza N, Malcangi V, Cohen J, Japiassu A, De Keulenaer BL, Daelemans R, Jacquet L, Laterre PF, Frank G, de Souza P, Cesana B, Gattinoni L: Incidence and prognosis of intraabdominal hypertension in a mixed population of critically ill patients: a multiplecenter epidemiological study. Critical care medicine 2005, 33(2):315-322.

41. Dalfino L, Tullo L, Donadio I, Malcangi V, Brienza N: Intra-abdominal hypertension and acute renal failure in critically ill patients. Intensive care medicine 2008, 34(4):707-713.

42. Sakka SG, Klein M, Reinhart K, Meier-Hellmann A: Prognostic value of extravascular lung water in critically ill patients. Chest 2002, 122(6):2080-2086.

43. Sturm JA, Wisner DH, Oestern HJ, Kant CJ, Tscherne H, Creutzig H: Increased lung capillary permeability after trauma: a prospective clinical study. The Journal of trauma 1986, 26(5):409-418.

44. Rubenfeld GD, Caldwell E, Peabody E, Weaver J, Martin DP, Neff M, Stern EJ, Hudson LD: Incidence and outcomes of acute lung injury. The New England journal of medicine 2005, 353(16):1685-1693.

45. Rivers EP, Kruse JA, Jacobsen G, Shah K, Loomba M, Otero R, Childs EW: The influence of early hemodynamic optimization on biomarker patterns of severe sepsis and septic shock. Critical care medicine 2007, 35(9):2016-2024

doi:10.1186/2110-5820-2-S1-S

Cite this article as: Cordemans et al:: Fluid management in critically ill patients: the role of extravascular lung water, abdominal hypertension, capillary leak, and fluid balance. Annals of Intensive Care 2012 2(Suppl 1): S1

\section{Submit your manuscript to a SpringerOpen ${ }^{\circ}$ journal and benefit from:}

- Convenient online submission

- Rigorous peer review

- Immediate publication on acceptance

- Open access: articles freely available online

- High visibility within the field

- Retaining the copyright to your article

Submit your next manuscript at $>$ springeropen.com 